\title{
Algebraic Thinking of Elementary Students in Solving Mathematical Word Problems: Case of Male Field Dependent and Independent Student
}

\author{
$1^{\text {st }} \mathrm{R}$ Ati Sukmawati \\ Computer Science Education \\ Lambung Mangkurat University \\ Banjarmasin, Indonesia \\ r.sukmawati@mhs.unesa.ac.id
}

\author{
$2^{\text {nd }}$ Akbar Sutawidjaja \\ Mathematics Education \\ Malang State University \\ Malang, Indonesia \\ akbar.sutawidjaja.fmipa@um.ac.id
}

\author{
$3^{\text {rd }}$ Tatag Yuli Eko Siswono \\ Mathematics Education \\ Surabaya State University \\ Surabaya, Indonesia \\ tatagsiswono@unesa.ac.id
}

\begin{abstract}
Algebraic thinking has an important role in solving problems, such as algebra, mathematics, science, and daily life problems. This paper is a case study on male elementary school students with field independent (LI) and field dependent (LD) cognitive style, with the aim of obtaining their algebraic thinking profile in solving math problems. This profile is required by the teacher as a foundation in designing a learning model or approach, and composing teaching materials that consider the heterogeneity of the cognitive style. Based on the results of the study, LI organizes all known data from the problem in a regular list, while $L D$ does not organize data. LI performs abstraction and modeling process by involving symbols that are free from context and symbols attached to the context, whereas LD only involves symbols attached to the context. When executing the trial-and-error strategy, LI selects randomly 11 as the first guess, and for the next guess rises two or two, while the $L D$ guesses randomly. The Subject of LI performs a structured trial-and-error strategy so that it is easily observed, while the LD is unstructured. LI performs a dynamic thinking process that works with unknown numbers by substituting an unknown value into the equation, whereas $L D$ calculates directly without substitution to the equation. (Abstract)
\end{abstract}

Keywords: Algebraic thinking, cognitive style, field dependent/ independent

\section{INTRODUCTION}

Algebra is a branch of mathematics taught in school mathematics. Algebra plays a very important role as a tool to solve advanced mathematical problems, science, business, economics, commerce, computing and other problems in everyday life. With algebra students are trained to think critically, creatively, reasonably and think abstractly, so by learning algebra will form students into a reliable problem solver. Because algebra is very important to learn advanced mathematics or other science, [8] emphasizes that all children have the opportunity to learn algebra.
In Indonesia, although algebra was introduced formally in the seventh grade of the first semester, but students in elementary schools have been introduced with some basic algebra ideas. For example, a fourthgrade student is asked to determine a number that satisfies an open sentence, such as " $24 \div \ldots=8$ " or "... $\times 2=\ldots "$. The activity of determining a number that satisfies an open sentence is the basic nature of algebra. In this activity, students must understand the properties of arithmetic operations and understand the relationship between arithmetic operations. According to Slavit [4], the ability to work with arithmetic operations will lead students to algebraic thinking.

Algebraic thinking is a way of thinking, which involves six mathematical thinking abilities consisting of: generalization, abstraction, analytic thinking, dynamic thinking, modeling, and organization [7]. This way of thinking is very useful in solving problems both in advanced mathematics, other fields of science and problems in everyday life. According to [7], this way of thinking can be introduced early, starting from elementary school.

Student's thinking profile in solving problems is closely related to how the student manages the information to solve the problem. Characteristics of a person in managing information is called cognitive style. Witkin distinguishes cognitive styles into fielddependent and field-independent cognitive styles [5]. As in [13] when solving problems, students with independent cognitive field styles tend to reorganize the information they receive, while students with dependent cognitive field styles receive information organizations as they are. Students with dependent cognitive field style tend to have more difficulties in separating relevant and irrelevant information [2]. The ability to organize information and distinguish between important and unimportant information, or that are relevant and irrelevant, is part of the indicator of algebraic thinking [7]. As expected, differences in 
cognitive styles will cause differences in students' algebraic thinking profiles.

The purpose of this paper is to reveal the algebraic thinking profile of field-independent male (LI) and field-dependent (LD) male students in solving mathematical problems. This profile is needed to be the foundation for the teacher in designing the model or approach of learning, and compile the teaching materials by considering the heterogeneity of students' cognitive style. As in [9], teachers should be sensitive to students' way of thinking in solving problems and are expected to consider such ways of teaching. Data about students' algebraic thinking profiles in solving problems, obtained through indepth interviews during and after the subject solved the problem. The problem solved by the subject is a mathematics word problem related to the equation. Audio and visual recording is also made as long as students solve problems and undergo interviews.

\section{A. Algebraic Thinking}

Algebra is not only an arithmetic with letters representing numbers, but algebra is another kind of thinking. As in [14], algebraic thinking is a way of thinking using symbols and mathematical tools to analyze different situations with; a) extracting information from the situation; b) represents the mathematical information with words, diagrams, tables, graphs, and equations; and c) interpret and apply mathematical findings, such as solving for unknown quantities, alleged assaying, and identifying functional relationships. Algebraic thinking in teaching primary school is the development of ways of thinking in the activities of analyzing the relationship between quantity, pay attention to structure, study change, generalization, problem solving, modeling, justifying, proving, and predicting. This way of thinking can use algebraic letters or symbols as a tool, or no use at all, but the ultimate goal to deliver students to more formal algebra [15]. Furthermore as in [7], algebra is a way of thinking that includes the ability of generalization, abstraction, analytical thinking, dynamic thinking, modeling, and organizing.

Generalization is the process of applying the arguments given into the larger context [3]. This process involves the claim that some trait or technique applies to a wider context. So the scope of claims is always greater than the set of pre-verified cases. Meanwhile, as in [7] generalization is a process to find patterns or forms. This process can be seen in the activity of recognizing patterns and relationships of a series of numbers and figures, solving problems using patterns found, or solving problems using a simplification strategy. There are two types of generalization of number patterns, namely algebraic generalizations and arithmetic generalizations [10]. Three steps must be passed in algebraic generalizations, namely (1) taking into account the similarities in the data given (2) forming and enacting common concepts based on the similarity noted for all sequences, (3) determining a common scheme or rule for all the tribes in the row. If step three fails then it is called arithmetic generalization. The generic rules that are made should be based on steps (1) and (2), if the general rule is made only by guessing or trial-and-error, then it can not be said as generalization, but induction.

Abstraction is a process that occurs when the subject focuses attention on the particular nature of the given object and then considers this property to be separate from the original [3]. As in [7], abstraction is a process for extracting objects and mathematical relations based on generalizations. The process of abstraction can be seen when understanding the concepts and properties of mathematics, using symbols related to concepts and properties, or operational activities with abstract symbols.

Analytical thinking is thinking about solving things (situations, practices, problems, statements, ideas, theories, arguments) into its component parts [12]. It involves the process of collecting relevant information and identifying key issues from basic information, linking and comparing data from multiple sources, identifying causal relationships, and drawing conclusions. According to [7] analytical thinking involves thinking processes related to processes used to find unknown values, such as solving equations with intuitive methods, solving equations with inverse operations, or solving problems using backward working. While dynamic thinking is a thought process related to the dynamic manipulation of mathematical objects, such as solving problems using trial-and-error strategies, identifying relationships between two sets [7].

Modeling processes to represent complex situations use mathematical expressions to investigate situations with models, and make conclusions [7]. According to [16], modeling is a cognitive activity that flexibly involves the use of multiple representations such as graphs, tables, and equations, and how the translations alternate between them. So modeling activities include making stories related to given expressions, creating problems related to given expressions, modeling situations using diagrams, equations or drawings.

Organizing is a thinking skill that helps take a systematic approach to problem solving by creating order. Organizing involves how to gather all the important information, make it easily accessible, and know how to use it for decision making. Organizing is a process of organizing complex situations using tables, and diagrams [7]. Through sorting and organizing data with tables, an overall picture of the problem and the relationship between problem conditions can be observed more easily. 


\section{B. Cognitive Style}

Cognitive style is a consistent individual characteristic in organizing and processing information so as to perceive, remember, think, and solve problems. Field-independent/ dependent cognitive style is a distinguished cognitive style based on the ability to separate items from their context [5]. As in [13], [1], and [2], field independent cognitive style is a cognitive style that easily retrieve information from long-term memory, having less difficulty separating information units from the whole context, more autonomous in imposing organizations on unstructured fields and tending to use problemsolving approaches in a more analytical way. While field dependent cognitive style is a cognitive style that is difficult to retrieve information from long-term memory, the difficulty of separating information units from the entire context, using field organization as it is given and tends to use the problem-solving approach in a global way.

\section{RESEARCH METHODS}

The research approach used is qualitative approach that is explorative. The subjects of this study were two male elementary school students. Subjects were selected on the recommendation of the classroom teacher, those students who had high math skills and the ability to communicate their thoughts. Subsequent subject candidates are given a math ability test, to select students with relatively equal mathematical abilities. Subject candidates with relatively similar mathematical abilities are then given a GEF test from [6] to determine their cognitive style. Then selected one subject with the FI-cognitive style and one subject with the FD cognitive style. The two students worked on the mathematical equation problem solving task which was validated by three mathematics education experts and two elementary school teachers. During and after completing the task, an in-depth, open and unstructured interview is conducted. Data analysis techniques are based on the concept of [11] which consists of data reduction activities, data display and conclusion drawing / verification. Time triangulation, increased persistence, discussion with peers, and multiplying references are used to obtain credible data. The problem that must be resolved is "Kamilah and her friends collected notebooks to be donated to an orphanage. Kamilah contributed 19 books, Hanifah contributed several books, Yulia contributed as much as Hanifah contributed, and Rasyidah contributed 23 books. After counting, the books were collected in total is four times the number of books donated by Hanifah How many notebooks have been collected by Kamilah and her friends?

\section{RESULTS}

This section discusses the results of a study comprising discussion of algebraic thinking profile of male field-independent and field-dependent in solving problems.

\section{A. Field-Independent Male Algebraic Thinking in Solving Problems}

After reading the problem without a voiceless LI can reveal directly known from the problem smoothly and correctly. The subject of LI may also be able to express the questioning in its own language, and may make some conclusions based on observations of the given facts. While understanding the problem, LI performs analytical thinking by gathering relevant information, identifying important things in the data, and drawing conclusionsthrough reading noiseless questions.

After reading the problem, LI organizes by writing all the facts of the matter in the form of a regular list so it is easier to understand. In this activity LI symbolizes the known aspect using a short sentence, the Kamilah's Book symbol representing the many books donated by Kamilah, the "?" Symbol for the unknown. So LI does an abstraction with the symbolization of the facts presented in the matter of using symbols that are still attached to the context, and using object names to represent the number of objects. The subject of LI performs a known factbased modeling process, connecting symbols to facts using the $"="$ operational operator and the " $x "$ operation symbol, and presenting information from the problem in the form of equations, with the total of books and Hanifah's books as unknown quantities.

After understanding the problem, then LI plans the problem solving by arranging several stages of completion.In this activity, LI performs an analytical thinking process by observing what data is already known and unknown but needed to solve the problem, so LI plans to solve the problem with the stages (1) find the number of books donated by Hanifah and the book donated by Yulia, (2) find all the books that Kamilah can collect. Furthermore, to count the number of books donated by Hanifah, LI is planning the problem solving by writing down two equations, the total books $=4 \times$ Hanifah's books , and, the total books $=(K$ 's books $+H$ 's books $+Y$ 's books $+R$ 's books). Based on these two equations, then LI wrote the third equation, the total books $=42$ $+n+n=m \div 4=n$. In this activity, LI performs a process of abstraction on an unknown quantity. Subject LI has started using symbols that are free from context, ie $n$ for Hanifah's books, and $m$ for the total number of books. Next do modeling activities by writing the equations using the operators "=", "+", $" \div "$, and " $\times$ ". LI converts the two equations he makes into one equation. He performs the abstraction process by understanding the commutative nature of the addition operation, and performing the analytical thinking process by collect similar tribes that is 
summing the known value. Furthermore because, the total number of books $=m$, then, $42+n+n=m$. LI states that since the total is equal to four times Hanifah's books, the result of $(m \div 4)$ must be equal to $n$. It means that LI solves equations with inverse operations. So LI performs an abstraction process by understanding the relationship between multiplication operations and division operations, modeling the connection completion procedure combining multiple stages of completion in one sentence mathematical. Next, LI is planning to use a trial-and-error strategy to find the value of $n$.

The next step, LI implement the problem-solving plan is to determine the number of books donated Hanifah with trial and error strategy. He performs an analytical thinking process when performing a trial and error strategy by observing the fact that the number chosen if multiplied by two and summed with 42 results should be divisible by four, then he selects randomly 11 as the initial number, and for the next guess rises two by two. LI also performs a dynamic thinking process using equation, $((2 \times$ Book $H)+$ $42) \div 4=n$, with substitution the value of Book $H$ which is different. Furthermore, LI performs a dynamic thinking calculates the final result by substituting the value of Book $H$ and Book $Y$ into the two equations it has made

Lastly LI re-examines the problem solving by checking the calculations mentally. Comparing the results of the first equation and the result of the second equation, since the result is the same then the LI feels confident that what it does is right. So LI's algebraic thinking profile when checking back is doing the analytical thinking process by recalculating mentally, and comparing the results of calculations from two different ways.

Based on the description, LI's algebraic thinking profile is analytical thinking through reading noiselessly, solving equations intuitively by systematic trial and error; abstracting the facts presented in the matter with embedded in context and context-free symbols, using short sentences as symbols and object names to represent the number of objects; presenting information of the problem in the form of pre-algebra and algebra equations; organizing all the information from the problem in the form of a regular list; dynamic thinking through solving equations using a trial and error strategy by substituting the value of the Book $H$ with different values, and calculating the final value by substituting the value of Book $H$ and Book $Y$ into the two equations it has made.

\section{B. Field-Dependent Male Algebraic Thinking in Solving Problems}

After reading the matter quietly $\mathrm{LD}$ is able to express firsthand what is known from the problem smoothly and correctly, revealing the questioned with his own language, and making some conclusions about the information he gets. This shows that through reading without a sound, LD performs an analytical thinking process so as to outline exactly what is known, asked, and make some fact-related conclusions. The next step, LD make a problem solving plan, and write an equation, Kamilah + Rasyidah + Yulia + Hanifah $=4 \times$ donated by hanifah.

LD uses the person's name as a symbol, ie, Kamilah represents donated by Kamilah. Thus LD has performed a process of abstraction to a known aspect of the problem by symbolizing what is known to use symbols that are still attached to the context, and using the name of the object to express the number of objects. LD processes the information given to the problem, and the problem to be solved, writes the information from the problem in the form of equation, with Yulia, Hanifah, and given donoted by Hanifah as an unknown number and uses the symbols $=$, " $\times$ ". LD performs the process of organizing the data begins by writing an equation to be resolved, then creating a list of known and unknown data. When asked how to find Hanifah's book value, LD mentions a trial-and-error strategy.

Furthermore, as planned, LD sums up many of the books donated by Kamilah and Rasyidah, then determines the number of books donated by Hanifah with a trial-and-error strategy. The following dialog describes how LD performs a trial-and-error strategy.

Q: How did you get it?

LD: If this is $19+23=42$, divided by 2, 21. Suppose Hanifah is 21, Yulia 21 also, the number is 42. Plus the 42 becomes 84 . While 21 times 4 is also 84 . The result is the same. So book Hanifahn 21

P: why should be divided by two?

LD: I do not know ma'am, because that's right Q: Did you work this way right from the start?

LD: no maam, tried, it turns out the same result Q: Try what?

LD: suppose Hanifah and Yulia 13, summed the result 26 , then added 42 result 68 . While 13 times 4 result 52 , not the same.

Q: how many times have you tried it?

LD: I tried several times with other numbers, but still wrong

Based on the above dialog, while executing the trial-and-error strategy, LD selects the number randomly, the number chosen multiplied by two is 
then added with 42 . The result is compared with the result of multiplying that number by four. If the same then the choice is correct. When implementing a trialand-error strategy, LD works with unknown numbers in the equation $(42+$ Yulia + Hanifah $=4 \times$ giving Hanifah) repeatedly with different Yulia and Hanifa values. According to [7], it can be said that LD conducted a dynamic thinking process. In this case, LD does not substitute into the equation but computes directly, which is purely arithmetic. LD also performs an analytical thinking process, comparing the results of the count $(42+$ Yulia + Hanifah $)$ and the result of $(4 \times$ Hanifah giving) to decide whether the guess is correct or not.

The last step, LD re-examine the results of the problem solving, checking the final results $19+23+$ $21+21$, and $21 \times 4$, mentally and sure enough because the result is the same. In this activity LD performs an analytical thinking process, which is doing mental recalculation and comparing the calculation results from two different ways.

Based on the description, LD's algebraic thinking profile is analytical thinking through reading noiselessly, solving equations intuitively by trial and error; abstraction by symbolizing the known and unknown quantities using symbols embedded in the context; presenting information of the problem in the form of pre-algebra equation; thinking dynamically through solving equations by trial and error in arithmetic.

\section{Discussion}

Based on the research results, the profile of algebraic thinking LI is analytical thinking, dynamic thinking, abstraction, modeling and organization, while the profile of LD algebraic thinking is analytical thinking, dynamic thinking, abstraction, and modeling. This enriches the results of [7] study which states that elementary school students can already be involved in thinking algebraically through analytical thinking, dynamic thinking, abstraction, modeling and organizing. Only subject LI organizes the information provided in the problem, while the LD does not organize the information provided. This is consistent with the opinion of [13] and [2] that field dependent subjects tend to use the organization as given, while field independent subjects tend to reorganize the data provided.

When solving problems, LI does abstraction by involving both symbols related to context and context-free, while LD uses only context-related symbols. This supports the results of [10] which states that students in primary schools can already be involved in symbolization using context-free symbols.

When carrying out a trial and error strategy, LI randomly guesses the first number then the next guess rises by two, while LD guesses randomly. This shows that $\mathrm{LI}$ is more analytical thinking than LD, in accordance with the opinion of [1] and [2] that field independent subjects tend to use more analytical problem solving than field dependent subjects.

\section{SUMMARY}

LI's algebraic thinking profile is analytical thinking through reading noiselessly and solving equations intuitively by systematic trial and error; abstracting the facts presented in the problem with embedded in context and context-free symbols; presenting information of the problem in the form of pre-algebra and algebra equations; organizing all the information from the problem in the form of a regular list; dynamic thinking through solving equations using a trial and error strategy by substituting the value of unknown.

LD's algebraic thinking profile is analytical thinking through reading noiselessly, solving equations intuitively by random trial and error; abstraction by symbolizing the known and unknown quantities using symbols embedded in the context; presenting information of the problem in the form of pre-algebra equation; thinking dynamically through solving equations by trial and error in arithmetic.

LI organizes all known data from the problem in a regular list, while LD does not organize data. LI performs abstraction and modeling process by involving symbols that are free from context and symbols attached to the context, whereas LD only involves symbols attached to the context. When executing the trial-and-error strategy, LI selects randomly 11 as the first guess, and for the next guess rises two or two, while the LD guesses randomly. The Subject of LI performs a structured trial-and-error strategy so that it is easily observed, while the LD is unstructured. LI performs a dynamic thinking process that works with unknown numbers by substituting an unknown value into the equation, whereas LD calculates directly without substitution to the equation. 


\section{REFERENCES}

[1] A. Altun and M. Cakan, "Undergraduate students' academic achievement, field dependent/independent cognitive styles and attitude toward computers," J. Educational Technology and Society, vol. 9, pp. 289, January 2006.

[2] BU. Onyekuru, "Field dependence-field independence cognitive style, gender, career choice and academic achievement of secondary school students in Emohua local government area of rivers state," J. Education and Practice. Vol. 6, pp. 76-85, 2015.

[3] G. Harel and D. Tall, "The general, the abstract, and the generic in advanced mathematics," For the learning of mathematics, vol. 11, pp. 38-42, February 1991.

[4] G. W. Ling and M. Ghazali, "Solution strategies, modes of representation and justifications of primary five pupils in solving pre algebra problems: an experience of using task-based interview and verbal protocol analysis," J. Science and Mathematics Education in Southeast Asia, vol. 30, pp. 45-66, Juny 2007.

[5] HA. Witkin and JW. Berry, "Psychological differentiation in cross-cultural perspective," ETS Research Bulletin Series, Juny 1975.

[6] H. A. Witkin, PK. Oltman, E. Raskin, SA. Karp, Embedded Figures Test. Palo Alto, 1971.

[7] H. C. Lew, "Developing algebraic thinking in early grades: Case study of Korean elementary school mathematics," The Mathematics Educator, vol. 8, pp. 88-106, 2004.

[8] National Council of Teachers of Mathematics, Principles and standards for school mathematics, 2000.

[9] J. Proulx, "Making the transition to algebraic thinking: Taking students' arithmetic modes of reasoning into account," delta-K44, vol.1, December 2006.

[10] L. Radford, "Algebraic thinking from a cultural semiotic perspective," Research in Mathematics Education, vol. 12, pp. 1-9, March 2010.

[11] MB. Miles and M. Huberman M, The Qualitative Researcher's Companion, Sage, March 2002.

[12] T. Thaneerananon, W. Triampo and A. Nokkaew, "Development of a test to evaluate students' analytical thinking based on fact versus opinion differentiation," International Journal of Instruction, vol. 9, pp. 123-138, July 2016.

[13] Y. Cao, Effects of field dependent-independent cognitive styles and cueing strategies on students' recall and comprehension, Virginia Tech, 2006, unpublished.

[14] K. Herbert and RH. Brown RH, "Patterns as tools for algebraic reasoning," Teaching
Children Mathematics, vol. 1, pp. 340-345, February 1997.

[15] C. Kieran, "Algebraic thinking in the early grades: What is it," The Mathematics Educator, vol. 8, pp. 139-151, August 2004.

[16] S. Lempp, Algebraic Reasoning for Teaching Mathematics, Madison, University of Wisconsin, 2008. 